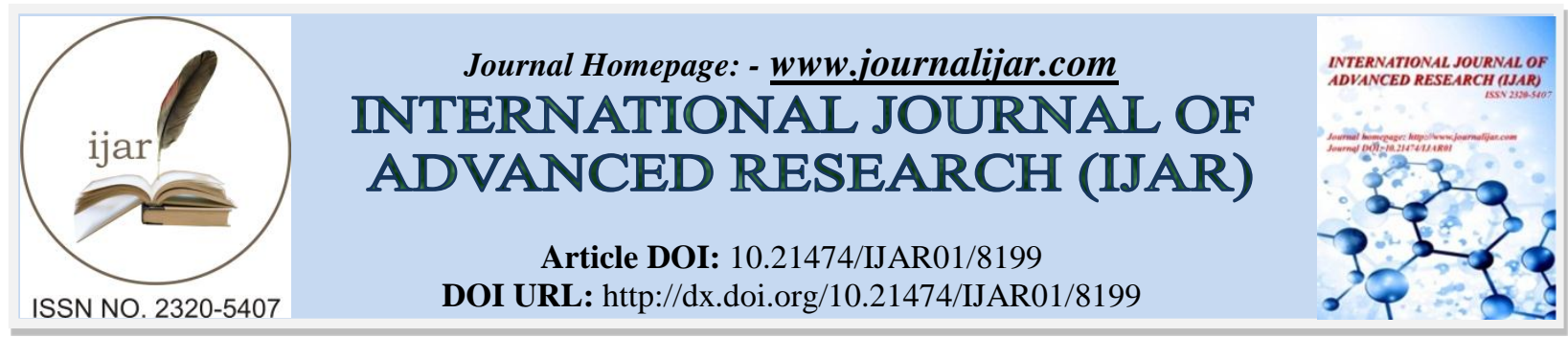

RESEARCH ARTICLE

\title{
BILATERAL BREAST HYPERTROPHY (GIGANTOMASTIA).
}

Sima Mohammad Al-Assaf and Saja Mohammad Al-Assaf.

Department of plastic and reconstructive surgery,king saud medical city (ksmc),kingdom of saudi arabia. Riyadh.

\section{Manuscript Info}

Manuscript History

Received: 12 October 2018

Final Accepted: 14 November 2018

Published: December 2018

\begin{abstract}
Gigantomastia is a rare condition characterized by excessive breast growth. It may occur spontaneously, during puberty or pregnancy, or while taking certain medications. There is no universally accepted definition of gigantomastia, but the majority of medical articles refer to a particular weight of excess breast tissue.Symptoms of gigantomastic may include mastalgia (breast pain), ulceration/infection, posture problems, back pain and chronic traction injury to 4th/5th/6th intercostal nerves with resultant loss of nipple sensation. It is also associated with decreased fetal growth, if it occurs during pregnancy.

The exact cause of gigantomastia is not known; however, hormonal and hereditary factors may be involved. Additionally, gigantomastia has been noted as a side effect of treatment with certain medications, such as like D-penicillamine. Treatment may include breast reduction, mastectomy with or without reconstruction, hormonal treatment, or a combination of treatments.
\end{abstract}

Copy Right, IJAR, 2018,. All rights reserved.

\section{Introduction:-}

Gigantomastia is a rare condition that causes excessive growth of the female breasts. Only a couple hundred cases have been reported in the medical literature.

The exact cause of gigantomastia isn't known. The condition can occur randomly, but it has also been seen to occur during puberty, pregnancy, or after taking certain medications. It doesn't occur in men.

While gigantomastia is considered a benign (noncancerous) condition, it can be physically disabling if not treated. In some cases, the condition resolves on its own, but many women with gigantomastia will need to have breast reduction surgery or a mastectomy.

43 years old woman from Sudan without chronic diseases came to our clinic complaining of increase in the size of her breasts, which affected her life and psychological. The size of her breasts began to increase during puberty when she reached the age of eleven and was accompanied by milk secretions, but did not care about the subject. When She was 25 years old and during her first pregnancy, she noticed a significant increase in the size of her breasts, but unfortunately she lost her fetus and for no reason. then she did investigation and found that the proportion of milk hormone too excessive with appeared in the result (pituitary adenoma) and then she did the operation. After she got out of the operation, there were some complications as she entered convulsions. Where the patient began to take medication and other drugs cortisone and treatment of convulsions. But she noticed that the size of her breast was increasing more than the previous after these medications. And continues to suffer with pain in the shoulder and

Corresponding Author:-Sima Mohammad Al-Assaf.

Address:-department of plastic and reconstructive surgery,king saud medical city (ksmc),kingdom 781 of saudi arabia. riyadh. 
back and inability to sleep comfortably. Her continuous visit to the hospital complained of an abscess where she did (I \& D) in her right breast 3 times and in her left breast twice. She wishes to remove her breasts completely because it caused her frustration and social isolation.

\section{Examination}

At the time of examination, both breast were extremely enlarged, reaching the umbilicus while in the standing position, the left breast was slightly larger than the right breast. The breast was disproportionately enlarged with widened areolas. The skin quality was good. The breast measurement

were as follows: suprasternal notch to nipple distance was $44 \mathrm{~cm}$ bilaterally, nipple to IMF distance was 23 at breast and 21 at right breast, and nipple to nipple distance was $30 \mathrm{~cm}$.

Breast ultra sonography and mammography demon strated but no abnormal signs. Laboratory studies including hormonal assay results, were normal. The patient underwent bilateral free NAC graft breast reduction . a total of $4.62 \mathrm{~g}$ tissue was removed

Figure 1:-Preoperative an terrier and lateral view the breast measurement was fellows suprasternal notch - to nipple distance was $44 \mathrm{~cm}$ bilaterally, nipple - to IMF distance was $23 \mathrm{~cm}$ at left breast and $21 \mathrm{~cm}$ at right breast, and

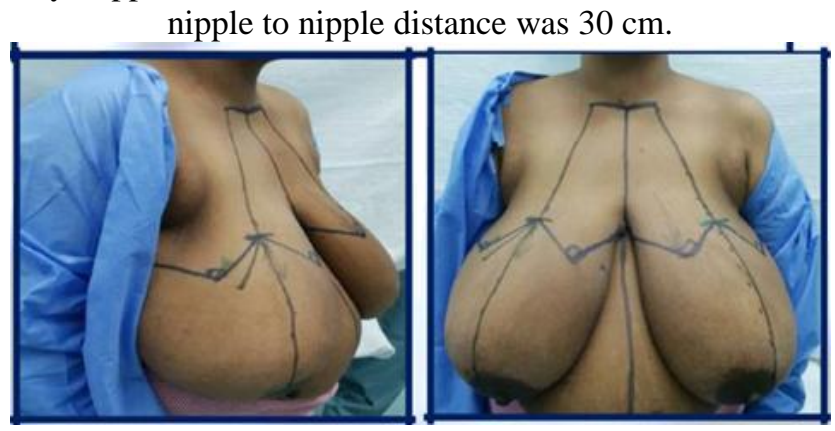

Figure 2:-Resected breast tissue. Total amount of 4.62 grams of tissue was removed right breast $=2.190$ grams, left breast $=2.420$ Grams).

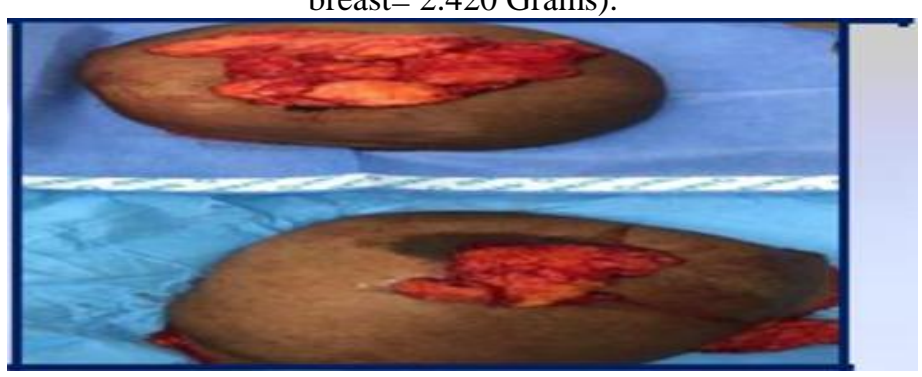

\section{Postoperative view}




\section{Treatment \\ Treatment Options}

There is no standard treatment for gigantomastia. The condition is usually treated on a case-by-case basis. Treatment is first aimed at treating any infections, ulcers, pain, and other complications. For example, antibiotics, warm dressings, and over-the-counter pain medications might be recommended. Pregnancy-induced gigantomastia might go away on its own after giving birth. However, in most cases, surgery is considered to reduce the size of the breasts.

\section{Surgery}

Surgery to reduce the size of the breasts is called breast reduction surgery. It's also known as reduction mammoplasty. Another type of surgery, known as mastectomy, has a much lower rate of reoccurrence. A mastectomy involves removing all of the breast tissue. After a mastectomy, you can get breast implants. However, mastectomy and implants may not be best treatment option due to the risk of complications. In addition, most women will not be able to breastfeed after a double mastectomy.

So doctor should discuss the risks and benefits to each type of surgery to the patient

\section{Discussion:-}

Many researchers define gigantomastia as a breast enlargement that requires reduction of 1,000 to 2,000 grams per breast.

1. Gestational or pregnancy-induced gigantomastia occurs during pregnancy. This subtype is thought to be triggered by pregnancy hormones, usually during the first trimester. It occurs in just 1 out of every 100,000 pregnancies.

2. Puberty-induced or juvenile gigantomastia occurs during adolescence (between the ages of 11 and 19), likely because of sex hormones.

3. Medication- or drug-induced gigantomastia occurs after taking certain medications. Most commonly, it's caused by a drug known as D-penicillamine, which is used to treat rheumatoid arthritis, Wilson's disease, and cystinuria.

4. Idiopathic gigantomastia occurs spontaneously, with no obvious cause. This is the most common type of gigantomastia.

The extreme breast enlargement and the excess weight of the breasts can result in physical complications, including:

1. over-stretching of the skin

2. skin rashes under the breasts

3. ulcers on the skin

4. neck, shoulder, and back pain

5. headaches

For example, teenagers with the condition may be harassed or embarrassed at school. This can lead to:

1. depression

2. anxiety

3. body image problems

4. avoidance of social activities

In pregnant women or women who have just given birth, gigantomastia can result in:

1. poor growth of the fetus

2. spontaneous abortion (miscarriage)

3. Suppression of the milk supply

\section{Conclusion:-}

If not treated, gigantomastia can lead to problems with posture and back problems, which can be physically disabling. It can also cause dangerous infections, body image issues, and pregnancy complications. In rare cases, a person with gigantomastia may need to have an emergency mastectomy because of complications. Gigantomastia doesn't cause cancer and doesn't spread to other parts of the body.Breast reduction surgery is considered a safe and 
effective treatment. However, research has shown that puberty and pregnancy-induced gigantomastia may reoccur after breast reduction surgery. Mastectomy offers a more definitive treatment for gigantomastia

Consent

Written informed consent was obtained from the patient for publication of this case report and any accompanying images.

\section{Completing Interests}

The authors declare that there is no conflict of interests regarding the publication of this paper.

\section{References:-}

1. Ohlsén, L.; Ericsson, O.; Beausang-Linder, M. (1996). "Rapid, massive and unphysiological breast enlargement". European Journal of Plastic Surgery. 19(6). doi:10.1007/BF00180324.

2. ^ Palmuth, T (1648). "Observations medicuarum centinae tres posthumae". Cent II (Obs 89). Braunschweig.

3. ^ Dafydd, H.; Roehl, K.R.; Phillips, L.G.; Dancey, A.; Peart, F.; Shokrollahi, K. (2011). "Redefining gigantomastia". Journal of Plastic, Reconstructive \& Aesthetic Surgery. 64 (2): 160doi:10.1016/j.bjps.2010.04.043. PMID 20965141.

4. ^ To Wo Chiu (2011). Stone's Plastic Surgery Facts and Figures (3rd ed.). Cambridge University Press. p. 188. 